\title{
Caracterização higiênico-sanitária e tecnológica dos pescadores e da tilápia do nilo (Oreochromis niloticus) comercializada no mercado municipal de Salinas-MG*
}

\author{
Hygienic-sanitary and technological characterization of fishermen and \\ Nile tilapia (Oreochromis niloticus) sold in Salinas-MG municipal market
}

\author{
Flaviana Antunes Sousa, ${ }^{* *}$ Romário Alves Rodrigues, ${ }^{* * *}$ Fábio Antunes Arruda, ${ }^{* * * *}$ Wagner Luiz Moreira dos Santos, ${ }^{* * * *}$ \\ Thiago Moreira dos Santos******
}

\begin{abstract}
Resumo
O objetivo deste trabalho foi realizar uma caracterização higiênico-sanitária e tecnológica dos pescadores de tilápia do Nilo (Oreochromis niloticus), e do produto comercializado no mercado municipal de Salinas. A caracterização foi realizada através da aplicação de questionário e visita in loco à prática da pesca e local de processamento do pescado. Após esse levantamento, foram coletadas amostras das tilápias diretamente no Mercado Municipal da cidade, nas mesmas condições de venda ao consumidor. Imediatamente as amostras eram levadas ao laboratório de microbiologia do IFNMG (Instituto Federal do Norte de Minas Gerais) - Campus Salinas em caixa isotérmica. As análises microbiológicas do produto foram baseadas na Instrução Normativa 62/2003 do Ministério da Agricultura e os resultados comparados com os padrões microbiológicos da Agência Nacional de Vigilância Sanitária. A maioria dos pescadores não possui ensino fundamental completo (65\%), a pesca é feita de forma artesanal em ceveiros na barragem de Salinas-MG, as etapas de processamento e venda são auxiliadas pelas esposas dos pescadores e só $20 \%$ possuem local específico para o beneficiamento do peixe. Constatou-se falhas higiênico-sanitárias e tecnológicas em várias etapas da cadeia produtiva. Detectou-se a presença de Staphylococcus aureus coagulase positiva, e altas contagens de coliformes e mesófilos, em grande parte das amostras coletadas. Ficou evidenciada a necessidade de maior controle higiênico durante as etapas de obtenção, processamento e comercialização da tilápia, muito pela falta de orientação/capacitação dos pescadores pelo poder público em Salinas/MG.
\end{abstract}

Palavras-chave: Boas práticas de fabricação, Pescado, Segurança alimentar

\begin{abstract}
The objective was characterize the tilápia do Nilo (Oreochromis niloticus) fishermen and their product in Salinas/MG municipal market. The characterization was made through an interview and visiting the location of fishery and processing the tilápia. After the survey fish samples were collected directly from the municipal market of Salinas-MG. These samples were immediately transported in an isothermal box to the laboratory where the microbiology analysis were made. All data were discussed based on federal legislation of the Agricultural Ministry and National Agency of Sanitary Vigilance. The results show that fishery of tilápia in Salinas/MG is made on a traditional way using fish ceiling in Salinas dam. Furthermore the fishermen have low study level, with $50 \%$ only with elementary school and are helped by their wifes. In the processing several steps have problems in hygienic techniques, like nonspecific fish processing place in $80 \%$ of the fishermen. Confirming this observation, the bacterial counting were elevated in Staphylococcus aureus and coliform proposed analysis. It is clear that the process must be more carefully made in all hygienic aspects during fishing, processing and commercialization of the tilapia. This situation is exacerbated by lack of training and guidance by trained institutions or state power related by fishermen.
\end{abstract}

Keywords: Fish, Food safety, Good Manufacturing practices

\section{Introdução}

O pescado é um alimento que se destaca nutricionalmente quanto à quantidade e qualidade das suas proteínas, à presença de vitaminas e minerais e, principalmente, por ser fonte de ácidos graxos essenciais do grupo ômega-3, eicosapentaenoico (epa) e docosaexaenoico (dha), associados à redução do risco de doenças cardiovasculares (Gonçalves, 2011).

\footnotetext{
${ }^{*}$ Recebido em 26 de julho de 2017 e aceito em 10 de dezembro de 2017.

**Médica Veterinária.

***Acadêmico do curso de Medicina Veterinária do IFNMG, Campus Salinas, Salinas/MG

****Médico Veterinário - IFNMG, Campus Salinas, Salinas/MG.

*****Docente da Escola de Veterinária da UFMG, DTIPOA, Belo Horizonte/MG.

******Docente do IFNMG, Campus Salinas, Salinas/MG Email: thiago.moreira@ifnmg.edu.br
} 
Apesar dessas características benéficas, o pescado, entre os produtos de origem animal, é um dos mais susceptíveis ao processo de deterioração, devido a atividade de água elevada, composição química, teor de gordura insaturadas facilmente oxidáveis e pH próximo a neutralidade. Entre os processos que podem levar à deterioração do pescado há a ação de enzimas autolíticas, a oxidação lipídica e a atividade bacteriana (Soares e Gonçalves, 2012).

Sendo assim, os pescados por serem altamente perecíveis, exigem cuidados especiais na manipulação, armazenamento, conservação, transporte e comercialização. Portanto, a qualidade do peixe fresco pode ser influenciada por métodos de captura, resfriamento, equipamentos e utensílios não higienizados e superfícies contaminadas, influenciando o grau de conservação e frescor do produto (Soares e Gonçalves, 2012).

Os contaminantes presentes no pescado podem ser classificados como microrganismos deteriorantes e patogénicos os quais são consequência de processamento e manipulação inadequada, contaminação fecal e são potencialmente capazes de provocar doenças e intoxicações ao consumidor (Pimentel e Panetta, 2003).

Em Salinas-MG a pesca é uma atividade que tem sido popularizada entre pessoas que têm dificuldades de inserção no mercado de trabalho ou visam complementar sua renda familiar. A barragem do Rio Salinas, criada para perenizar o rio e abastecer a cidade, é o principal ponto de pesca. Neste local, os pescadores capturam, principalmente, a tilápia, a traíra e o tucunaré, para venda e comercialização no Mercado Municipal. Neste ponto, muito frequentado por turistas e moradores de cidades circunvinhas, já que a cidade é um polo de agricultura familiar justamente por causa do Mercado e sua estrutura de comércio, a venda do pescado é feita diretamente ao consumidor. Essa venda, feita em barracas improvisadas sob o sol, tem pouca interferência da vigilância sanitária local.

Baseado nesses aspectos, este trabalho teve por objetivo avaliar a qualidade higiênico-sanitária e microbiológica do pescado comercializado no mercado municipal de Salinas.

\section{Material e Métodos}

A caracterização dos pescadores se deu a partir de visitas nos pontos de vendas no mercado municipal de Salinas-MG e de aplicação dos questionários. Visitouse os locais de pesca na barragem de perenização do Rio Salinas e as residências dos pescadores onde é feito o beneficiamento da tilápia. Selecionou-se para o estudo apenas os pescadores artesanais que desenvolvem todo o processamento do pescado, desde a despesca até a comercialização e que assinaram o termo de consentimento excluindo aqueles que somente fazem a comercialização (atravessadores) no mercado municipal de Salinas-MG. Os produtores foram identificados, aleatoriamente, com letras de "A" a "I". Foi aplicado um questionário investigativo com questões relacionadas às técnicas de pesca, transporte, estocagem nas residências e durante a comercialização, processamento do pescado, e aspectos gerais relacionados à higiene na manipulação e sanificação dos equipamentos, utensílios e ambiente. Adicionalmente, durante a execução do trabalho foi acompanhado um dia de pesca onde se analisou as etapas de captura, evisceração e transporte até as residências para observar a filetagem, embalagem e refrigeração do pescado.

Para a caraterização microbiológica, foram coletadas nos pontos de venda um total de dezoito amostras, de maneira aleatória, entre os nove pescadores cadastrados, duas amostras por semana, aos sábados por ser o principal dia de comercialização. Após passar por uma inspeção visual para identificar o estado de conservação e evisceração, coletou-se um peixe inteiro (uma amostra) por pescador e acondicionou-se em isopor com gelo para manter em refrigeração. As análises de contagem de mesófilos e psicrotróficos, Staphylococcus aureus e coliformes a $30^{\circ} \mathrm{C}$ e $45^{\circ} \mathrm{C}$ foram conduzidas no laboratório de Microbiologia da Unidade Educativa de Produção Agroindústria do Instituto Federal do Norte de Minas Gerais (IFNMG) - Campus Salinas de acordo com a metodologia oficial do Ministério da Agricultura (Brasil, 2003) e comparadas com o padrão previsto na legislação do Ministério da Saúde (Brasil, 2001),

\section{Resultados e Discussão}

A compilação dos principais resultados do diagnóstico dos pescadores artesanais de Salinas está ilustrada na Figura 1. A baixa escolaridade e a falta de capacitação ou conhecimentos básicos de medidas de higiene durante o processamento, estocagem e comercialização, em um universo onde $55 \%$ dos participantes da pesquisa têm na pesca sua única fonte de renda, demonstra uma fragilidade no processo para garantia da qualidade do produto final.

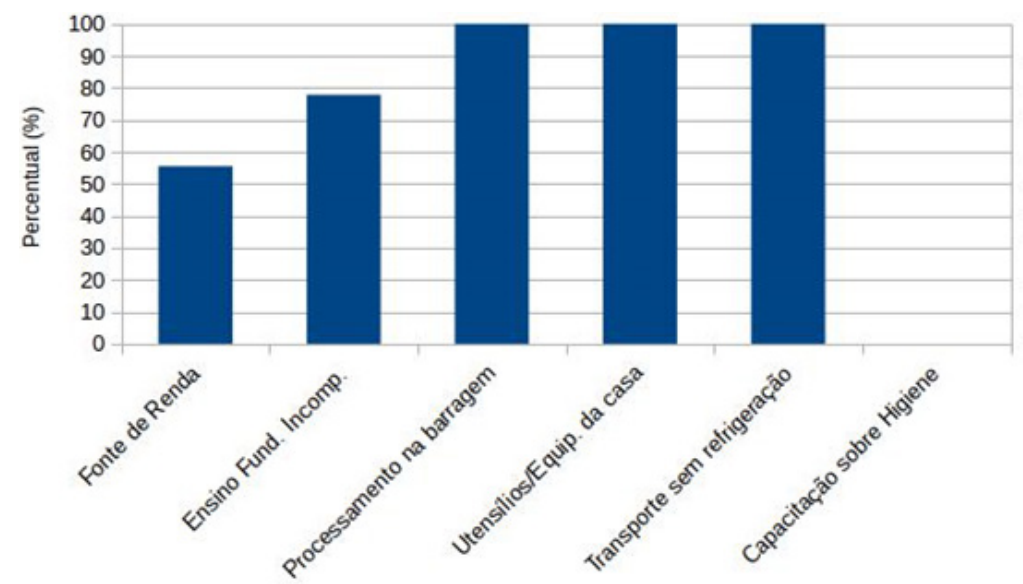

Figura 1: Diagnóstico dos pescadores artesanais de tilápia na cidade de Salinas-MG

Com relação ao processamento do pescado, todos os pescadores fazem a evisceração e lavagem dos peixes já no local de pesca, usando a água da barragem de Salinas. Além disso, apenas $22,2 \%$ dos pescadores possuem um local adequado para filetagem e estocagem. Geralmente trabalham com equipamentos, utensílios, água tratada e produtos de limpeza comuns ao uso da cozinha da residência, desconhecem as medidas básicas de segurança do trabalho e de higienização (Figura 1). Esses fatores podem favorecer a ocorrência de contaminação cruzada, aumentando a carga microbiana do 
produto final. Resultados semelhantes foram constatados por Pinto et al. (2012), ao avaliar as condições de manipulação de pescado no mercado municipal de Teresina/PI.

Nenhum deles utiliza equipamentos de segurança (EPIs) durante a captura, evisceração e filetagem. O meio de transporte principal é a bicicleta, com um tempo médio para o transporte do local da pesca até às residências de 50 minutos, utilizando caixas plásticas sem gelo (Figura 1). Diferentemente deste trabalho, Barreto et al. (2012) constataram que o transporte do pescado até o mercado municipal de Cruz das Almas/BA, é feito com veículos (próprio ou coletivo) utilizando caixa de isopor com gelo. O resfriamento é etapa de fundamental importância para a conservação da qualidade do pescado (Gonçalves, 2012) e deve ser adotada com água potável, na forma e proporção adequadas e mantido o mais próximo de $0^{\circ} \mathrm{C}$ possível (Zanini et al., 2001).

Os resultados das análises microbiológicas das amostras de tilápia (Oreochromis niloticus) obtidas dos pescadores artesanais de Salinas/MG estão listadas abaixo (Tabela 1).

Tabela 1: Análises de mesófilos, psicrotróficos, Staphylococcus aureus (UFC/g) e coliformes a $30^{\circ} \mathrm{C}$ e a $45^{\circ} \mathrm{C}(\mathrm{NMP} / \mathrm{g})$ de amostras de tilápia oriundo da pesca artesanal do município de Salinas-MG

\begin{tabular}{cccccc}
\hline Amostras & Mesófilos & Psicrotróficos & $\begin{array}{c}\text { S.aureus coagulase } \\
\text { positivo }\end{array}$ & \multicolumn{2}{c}{ Coliformes } \\
\cline { 5 - 6 } & & & $30^{\circ} \mathrm{C}$ & $45^{\circ} \mathrm{C}$ \\
\hline A & $3,0 \times 10^{7}$ & $1,8 \times 10^{6}$ & $2,5 \times 10^{6}$ & 460 & 460 \\
B & $3,7 \times 10^{4}$ & $1,6 \times 10^{4}$ & $1,5 \times 10^{5}$ & 27 & 36 \\
C & $2,6 \times 10^{4}$ & $1,9 \times 10^{4}$ & $4,1 \times 10^{4}$ & 29 & 27 \\
D & $2,7 \times 10^{4}$ & $1,4 \times 10^{4}$ & $4,3 \times 10^{4}$ & 120 & 43 \\
E & $2,4 \times 10^{4}$ & $1,1 \times 10^{4}$ & $3,5 \times 10^{6}$ & 43 & 38 \\
F & $7,2 \times 10^{7}$ & $3,5 \times 10^{6}$ & $1,2 \times 10^{6}$ & 1100 & 1100 \\
G & $2,8 \times 10^{7}$ & $1,0 \times 10^{6}$ & $4,2 \times 10^{4}$ & 120 & 43 \\
H & $9,1 \times 10^{7}$ & $4,1 \times 10^{6}$ & $7,7 \times 10^{4}$ & 43 & 43 \\
I & $8,5 \times 10^{7}$ & $5,8 \times 10^{6}$ & $1,2 \times 10^{6}$ & 460 & 460 \\
\hline
\end{tabular}

Os resultados encontrados para as amostras A, F, G, H e I, apresentam contagens dos microrganismos avaliados acima de $106 \mathrm{UFC} / \mathrm{g}$, podendo ter como causas as condições de temperatura na ocasião da coleta das amostras, em torno de $+10^{\circ} \mathrm{C}$, enquanto as demais estavam conservadas congeladas a $-5^{\circ} \mathrm{C}$. Além disso, durante as visitas in loco, notou-se que nos refrigeradores onde acondicionavam o pescado, havia outros alimentos (carne bovina e ou de frango, sobras de comida doméstica, entre outras), caracterizando assim uma possível fonte de contaminação cruzada. Os pescadores $\mathrm{H} \mathrm{e}$ I apresentavam condições deficientes de higiene no barco, vasilhames de armazenamento e transporte do local da captura até a residência, onde realiza a manipulação e beneficiamento.

Os resultados encontrados assemelham-se aos encontrados por Santos et al. (2008) analisando piramutaba congelada, por Barreto et al. (2012) em pescados frescos, congelados e salgados, e por Soares et al. (2012) em filés de tilápia. Altas contagens de mesófilos e/ou psicrotróficos são associados a condições higiênicas deficientes nas etapas de processamento, empacotamento e estocagem dos produtos. Adicionalmente, em estudo realizado por Agnese et al. (2001), observou-se que pescados que apresentaram mesófilos superiores a $106 \mathrm{UFC/g}$ são considerados críticos com relação ao grau de frescor do produto.

As comissões internacionais, como a International Commissionon Microbiological Specifications Foods (ICMSF), (1986), preconizam como padrão microbiológico a contagem de microrganismos mesófilos máxima de $107 \mathrm{UFC/g}$ para pescado refrigerado. A legislação brasileira não prevê limites para a contagem de bactérias aeróbias mesófilas em pescado (Brasil, 2001)

Com relação às contagens de Staphylococcus aureus, foram constatadas contagens superiores (Tabela 1) ao permitido pela legislação brasileira (Brasil, 2001), indicando que os procedimentos de manipulação no pescado in natura foram feitos de forma inadequada. Este fato corrobora o observado na visita ao local de processamento onde as condições higiênicosanitárias de manipulação, processamento e estocagem foram consideradas inadequadas, favorecendo a contagem elevada. Segundo Vieira (2003), o manipulador é o principal responsável pela contaminação através do manuseio, saliva e secreções.

Resultados semelhantes foram encontrados por Rocha et al. (2013), onde $73 \%$ das amostras de filés de tilápia, comercializadas no mercado municipal de Currais Novos-RN, estavam impróprias ao consumo devido à presença de Staphylococcus aureus coagulase positiva. Contrastando com este estudo, Soares et al. (2012) não encontraram Staphylococcus aureus em filés de tilápia armazendadas em gelo em Apodi-RN, demonstrando boa qualidade higiênico-sanitária do ambiente de captura e manipulação.

Nos resultados encontrados para coliformes (Tabela 1) nota-se um elevado crescimento nas amostras, especialmente oriundas dos pescadores A, F e I. Apesar da legislação brasileira não estabelecer parâmetros para coliformes, a ICMSF (1986) recomenda um limite de 4 x 102 NMP/g para coliformes totais e fecais, sendo classificadas portanto de baixa qualidade. No processamento desses pescadores, foi constatado uso de água de má qualidade na hora da evisceração (oriunda da própria barragem), somado às deficientes condições higiênico-sanitárias na manipulação já relatadas, influenciando na alta enumeração. Falhas ocorridas durante a captura (ambientes com poluição fecal), manipulação, armazenamento, transporte e beneficiamento, podem ser responsabilizados pela ocorrência de coliformes em pescado (Vieira, 2003).

No trabalho de Makilla (2014), avaliando a qualidade microbiológica de tilápia na Nigéria, resultados foram semelhantes somente em um dos três mercados avaliados. Já Silva et al. (2016) encontraram resultados inferiores aos deste trabalho, variando de 0,477 a 1,509 NMP/g em tilápias comercializadas em mercados públicos de Mossoró-RN. 


\section{Conclusões}

A tilápia comercializada no Mercado Municipal de Salinas-MG possui alta carga microbiana. Essa má qualidade microbiológica

\section{Referências}

AGNESE, A. P.; DE OLIVEIRA, V. M.; SILVA, P. P. O.; OLIVEIRA, G. A. Contagem de bactérias heterotróficas aeróbias mesófilas e enumeração de coliformes totais e fecais, em peixes frescos comercializados no município de Seropédica - RJ. Revista Higiene Alimentar, São Paulo, v. 15, n. 88, p. 67-70, 2001.

BARRETO, N.S.E.; MOURA, F.C.M.; TEIXEIRA, J.A.; ASSIM, D.A.; MIRANDA, P.C. Avaliação das condições higiênicosanitárias do pescado comercializado no município de Cruz das Almas, Bahia. Revista Caatinga. Mossoró, v.25, n.3, p.86-95, 2012.

BRASIL. Ministério da Saúde. Resolução RDC n¹2 de 02/01/2001. Aprova o Regulamento Técnico sobre padrões microbiológicos para alimentos. Brasília: Ministério da Saúde, 2001.

BRASIL. Ministério da Agricultura. Secretaria Nacional de Defesa Agropecuária. Instrução Normativa n 62 de 26/08/2003. Oficializa os Métodos Analíticos oficiais para análises microbiológicas para controle de produtos de origem animal e água. Brasília: Ministério da Agricultura, Pecuária e Abastecimento, 2003.

GONÇALVES A.A., editor. Tecnologia do pescado: ciência, tecnologia, inovação e legislação. São Paulo: Atheneu; 2011.

ICMSF (INTERNATIONAL COMMISSION ON MICROBIOLOGICAL SPECIFICATIONS FOR FOODS). 2. Sampling for microbiological analysis: principles and specific applications. 2. Ed. London: Blackwell Scientific Publications, 1986.131p.

MAKILLA, D.M. Fish Quality Survey: Staphylococcus aureus and Salmonella spp occurrence in Nile Tilapia at informal markets of Nairobi. Food Science and Quality Management, Vol.33, 2014.

PIMENTEL, L. P. S.; PANETTA, J. C. Condições higiênicas do gelo utilizado na conservação de pescado comercializado em supermercados da grande São Paulo. Parte 1, resultados está relacionada com a baixa escolaridade e falta de capacitação dos pescadores artesanais, responsáveis pelo fornecimento e comercialização do produto, acarretando em falhas básicas de higiene durante toda a cadeia produtiva local.

microbiológicos. Higiene Alimentar, v. 17, n. 106, p. 56-63, 2003.

PINTO, L. I. F.; BORGES, M. J.; ABREU, M. M.; CASTRO, S. A.; ALENCAR, G. R. R.; FEITOSA, R. G. N. Avaliação das condições higiênico-sanitárias das bancas de Comercialização de peixe no mercado do peixe na cidade de Teresina-PI. 2012. VII Congresso Norte Nordeste de Pesquisa e Inovação (CONNEPI). 17 p.

ROCHA, F. A. G.; ARAÚJO, L. O.; ALVES, K. S. DANTAS L. Í. S.; SILVA, R. P.; ARAÚJO, M. F. F. Estafilococos coagulase positivos em filés de tilápia (Oreochromis niloticus) comercializados no mercado modelo Nerival Araújo, Currais Novos/RN. 8 p. 2013.

SANTOS, T.M.; MARTINS, R.T.; SANTOS, W.L.M.; MARTINS, N.E. Inspeção visual e avaliações bacteriológica e físico-química da carne de piramutaba (Brachyplatistoma vaillanti) congelada. Arq. Bras. Med. Vet. Zootec., v.60, n.6, p.1538-1545, 2008.

SILVA, R.X.; ABRANTES, M.R.; NASCIMENTO, J.P.A.; PINHEIRO, C.G.M.E.; FILGUEIRA, C.L.P.; SILVA, J.B.A. Qualidade higiênico-sanitária da tilápia (Oerochromis spp.) fresca e congelada em mercados públicos. Ciência Animal Brasileira, v.17, n.4, p.574-580, out./dez. 2016.

SOARES K.M.P., GONÇALVES A.A. Qualidade e segurança do pescado. Rev Inst Adolfo Lutz. São Paulo, 2012; 71(1):1-10.

SOARES, K.M.P.; GONÇALVES, A.A.; SOUZA, L.B.; SILVA, J.B.A. Pesquisa de Staphylococcus aureus em tilápia do nilo (Oreochromis niloticus) armazenada em gelo. Acta Veterinaria Brasilicia, v.6, n.3, p.239-242. 2012.

VIEIRA, R.H.S.F. Microbiologia, higiene e qualidade do pescado: teoria e prática. São Paulo: Varela, 2003. 380p.

ZANINI M.S., MARTINS J.D., TORRES A., TOBIAS F.L. Avaliação microbiológica do gelo de balcão frigorífico de peixarias da grande Vitória-ES. Hig Aliment. 2001; 15(80/81):122. 